\title{
Ivan Petrovitch Pavlov, For.Mem.R.S.
}

IVAN Petrovitch PAvLov died in his eighty-seventh year on February 27 , 1936. His life was not only rich in years; it was fruitful in original ideas and in work accomplished. No complete account of his achievements can be attempted here. Only the principal lines of investigation which Pavlov followed and his general conception of the principles underlying the functioning of the animal body will be discussed.

Notwithstanding that Pavlov worked in many different territories of physiology, he was guided throughout all his researches by the same general idea, which may be described as the principle of "synthetical physiology," or (to use the term which I believe has been suggested by Professor I. de Burgh Daly of the University of Edinburgh) "integral physiology." While "analytical physiology" aims at decomposing a phenomenon into its component parts and giving them a physical or chemical or physico-chemical explanation, "synthetical" or "integral physiology," using similar methods, takes the whole body into consideration and relates its findings to the organism as a whole. Thus, though there is little difference in the method of investigation in either case, the ultimate aim is not the same. It was Claude Bernard who particularly encouraged this integrative tendency. Nobody, perhaps, has contributed more to its experimental foundation and development than Pavlov, although the same tendency is to be found in the work of other outstanding physiologists; C. S. Sherrington, J. S. Haldane, W. B. Cannon, for example, may be mentioned in this connection. Many physiological laboratories to-day, instead of direct experimentation on animals, largely employ physico-chemical and physical methods in analysing the more basal functions of living cells, tissues, and organs. Important as the analytical method may be, it can in itself offer but an incomplete picture of the life processes. These are usually the outcome of a complex interplay of phenomena, and only after integration of the analytical results can a satisfying conception be obtained. The day will come when the most elaborate physical and chemical explanations of separate physiological phenomena will no longer satisfy the investigator. No function of the body is independent of others, and every function is continually changing with the changing conditions of the body. A striking example of mutual influence in the function of various organs is afforded by the physiology of the endocrine glands. Integral physiology can help us to 
correlate the functions of different organs and to build up a conception of the organism as a whole. Furthermore, it will form the basis of a true physiological medicine, since medicine has always to deal with the body as a unit.

According to Pavlov, an animal body is an extremely unstable system, which must constantly maintain its equilibrium with the outer world. To every external change, whether the most insignificant or one which threatens to destroy the whole organism, it replies with definite reactions - that is, with a change, or successive changes, in its activities. A constant neutralization of the effects of changes occurring in the outer world, as well as within the body itself, is thus accomplished. Therefore, in referring to the physiological, or normal, function of an organ, we must, strictly speaking, take into consideration the functional state of all the other systems and organs of the body. Incidentally, this conception of the living organism made Pavlov very critical regarding the "method of acute experiment." He always, of course, recognized its great importance in physiology, but he never tired of repeating that the condition of an animal or an organ during such experiments is often far removed from the normal. This incited him, in his investigations on the digestive glands, to work out a special method involving the establishment of "permanent fistulæ" in the gastro-intestinal tract. He was the first to organize a special aseptic department in his laboratory for the purpose of applying the "method of physiological surgery." An aseptic department such as this is now a necessary adjunct to every experimental physiological and pathological laboratory.

It is easy to understand how this conception of the regulation of the bodily activity led Pavlov, especially in his earlier work, to the idea of the purposiveness (German, Zweckmässigkeit) of physiological phenomena. In his book, The Work of the Digestive Glands, he speaks very often of the "purpose" of one or another secretory activity of the glands, especially when the problem of their adaptation to different types of stimuli is discussed. At the beginning of the Third Lecture, for instance, he says that "the gastric and pancreatic glands have what at first sight appears to be a form of instinct" (Pavlov-translation by Thompson-2nd edition, p. 48). In the original Russian text (p. 56) this idea is even more strongly expressed, the word translated as "instinct" actually implying mind or intelligence. This attitude towards the interrelation of the phenomena observed in the animal body caused some people to criticize Pavlov for holding a teleological conception of life. Such criticisms seemed to me to be unjustified. Pavlov never believed in a special plan of creation or in the theory that development is caused by 
the purposes which things serve. For him "purposiveness" signified the finest adaptation of the animal to its environment or of an organ or tissue to the functional state of the rest of the organism.

The scientific heritage left to us by Pavlov is indeed stupendous. Its value lies not only in the multitude of new facts which he discovered, but even more in the new methods which he evolved and which led him, and will lead generations of physiologists, to a better understanding of the complex machinery of the animal body. Three fields of physiology chiefly engaged Pavlov's attention. In the early days of his career he was interested in problems concerning the circulation of the blood (regulation of the blood-pressure; innervation of the heart). Later he devoted himself to the study of the secretion of the digestive glands; and during the last thirty years his whole attention was concentrated on the study of the central nervous system by the method of conditioned reflexes.

Physiology of the Heart.--Independently of Gaskell; Pavlov discovered in 1882-83 (Archiv für (Anat. und) Physiol., 1887, p. 498) that stimulation of the sympathetic nerve to the heart in the dog not only accelerates the heart-beat but increases its force. By stimulating separate branches of the sympathetic nerve he found one which produced a "pure augmentor" effect, i.e., a positive inotropic effect, without producing a positive chronotropic effect. The augmentor effect of sympathetic stimulation was not due, as succeeding investigations showed, to the increased volume of blood filling the heart. Pavlov and Gaskell were, therefore, the discoverers of a new function of the sympathetic cardiac nerves, namely, their dynamic function. The original conception of Pavlov that the heart is supplied by two pairs of nerves, deriving from the sympathetic and the vagus respectively- "rhythmic" (accelerator and inhibitory nerves) and "dynamic" (augmentor and "abator" nerves)has required modification in view of modern developments in cardiology and the discovery of chemical transmitters of nerve impulses. Nevertheless the fundamental fact of the dynamic function of the cardiac nerves remains unshaken.

Digestive Glands.-In the course of some fifteen years, from the end of the eighties of last century to the opening years of the present century, Pavlov entirely reconstructed the physiology of the digestive glands and laid a solid foundation for further investigations in this field. His achievements were crowned in 1904 with the award of the Nobel Prize. He was the first physiologist to be thus honoured. The results of his investigations were published in 1897 in the form of a book (in Russian). This was later translated into German and French, while an English translation 
by W. H. Thompson appeared under the title of The Work of the Digestive Glands in 1902 , and a second edition in 1910.

It is usually thought that the incentive towards this work and towards the use of permanent fistulæ and isolation of parts of the alimentary canal as a special physiological method was acquired by Pavlov in R. Heidenhain's laboratory. This is only partly true. When Pavlov visited Montreal and McGill University in I929, he picked up from a shelf in the library of the Physiological Laboratory G. H. Lewes' Physiology of Common Life (vol. i, I 859), opened it at p. 230, and showed us a diagram of the gastro-intestinal tract. "When in my very young days I read this book (in a Russian translation)," he said, "I was greatly intrigued by this picture. I asked myself: How does such a complicated system work? My interest in the digestive system originated at this epoch."

Heidenhain was not the first to employ the method of permanent fistulæ and isolation of parts in the study of the gastro-intestinal tract. Attempts had already been made in this direction by Thiry, Klemenzievitch, and others. There is no doubt, however, that Pavlov's sojourn in Heidenhain's laboratory greatly stimulated the interest of the young physiologist in a field which had previously attracted his attention.

Pavlov was always eager to use new methods in the investigation of his problems, and he did so in studying the function of the alimentary canal. Notwithstanding his brilliant operative technique in "acute experimentation," he largely employed the method of "physiological surgery," which permitted him to keep the animals for years under practically normal conditions and in good health. One of the most remarkable achievements of "physiological surgery" is the "Pavlov pouch," formed by isolation of a part of the stomach from the rest of the organ, the innervation of the isolated portion being allowed to remain intact. This and many other most ingenious operations on the alimentary canal furnished Pavlov with an unprecedented method for the study of gastric function. The discovery of facts of first-class importance followed one another in uninterrupted succession.

The following brief summary of the facts discovered by Pavlov will show how greatly he added to our knowledge. The innervation of the gastric, pancreatic, and intestinal glands was clearly demonstrated by him. The quantitative and qualitative characteristics of the salivary, gastric, pancreatic, and other glandular secretions were determined. The three phases of gastric secretion-nervous (unconditioned and conditioned), chemical pyloric, and chemical intestinal-were discovered. It was found that fat and acid inhibit the secretion of the gastric glands but stimulate the secretion of the pancreatic gland. A new theory 
concerning inhibitory-secretory nerves was put forward. The detoxicating function of the liver was revealed by study of the effects of a meat diet on dogs with an Eck fistula. Enterokinase was discovered, and so on. Very many of Pavlov's findings are now included in every text-book of physiology, often without any mention of his name. They have become matters of common knowledge-a proof of their fundamental value.

Pavlov's work on the digestive glands was based on two theories: (I) that of the specific excitability of the sensory nerve-endings in the alimentary canal, and (2) that of the exclusively nervous character of the mechanism regulating the activity of these glands. In relation to the first, Pavlov had to contend with the then universally accepted idea of the general excitability of the alimentary canal, whereby presumably any chemical or mechanical stimulant present in the gastro-intestinal tract could activate the secretion of the digestive glands. In opposition to this crude and barren idea Pavlov advanced the theory of the specific excitability of the sensory nerve-endings in the alimentary canal, according to which a secretory response to definite stimuli occurs only in certain glands and under special conditions which vary in different parts of the canal. Time has brought some important modifications to this conception, nevertheless in general it was undoubtedly correct.

Pavlov's second supposition-that concerning the purely nervous mechanism of the secretory processes-had to undergo fundamental alteration. Since the discovery of secretin by Bayliss and Starling in I902, we know that coexistent in the alimentary canal are two mechanisms which regulate its work: a nervous and a humoral. In discussing this fact one must not forget that the bulk of the work performed by Pavlov and his co-workers on the digestive glands was done in the eighties and nineties of last century. Endocrinology was then only a scientific baby, noisy at times, yet inarticulate. Humoral pathology was taboo, and the almighty nerves were supposed to regulate the whole life.

I well remember the time when we first learned about Bayliss and Starling's discovery. There was great excitement in the laboratory. Professor Pavlov asked one of his assistants, Dr Savitch, to repeat their experiment. The effect of secretin was evident and clear cut. Pavlov silently watched the experiment, then without a word he left the room and went to his office. In half an hour he came back and said: "Of course they are right. It is clear that we cannot pretend to the exclusive right of discovering new facts." From then on he unreservedly admitted the existence of a dual mechanism regulating the secretory activity of some of the digestive glands.

I am inclined to think that the discovery of the hormonal mechanism 
in pancreatic secretion and soon after of analogous mechanisms participating in the activity of other glands diverted Pavlov's interest from the alimentary canal. It happened that at this period (1901-02) Pavlov began to show interest in the "psychic secretion" of the salivary glands. The discovery of "hormones" probably accelerated his transition from one field of investigation to the other. From this time on, his thoughts were more and more occupied with "conditioned reflexes."

Conditioned Reflexes.-Even more startling than Pavlov's achievements in the physiology of the digestive glands was his application of physiological methods to the study of the function of the cerebral hemispheres, by means of conditioned reflexes. This may, indeed, be considered a revolutionary step, for in a province of science hitherto regarded as the almost exclusive domain of psychology Pavlov ventured to employ physiological methods of investigation and to evaluate his results from a purely physiological point of view. Little was known regarding the function of the cerebral cortex before Pavlov introduced his method of conditioned reflexes. The effects of electrical excitation of the motor area, discovered by Fritsch and Hitzig in 1870 ; the rough localization of the sensory areas, originally established by Ferrier and Munk; and the fact that an animal could be kept alive after removal of both hemispheres (as demonstrated in Goltz's famous dog)-this was practically all the knowledge then available on the subject. The presence in the cortex of special "associative" centres was admitted by some investigators but denied by others (for example, Munk). As to the interpretation of the data obtained after the extirpation of different parts of the cortex, it was anything but physiological. Goltz considered the abnormal behaviour of his dog to be the result of a "loss of intelligence." Munk asserted that "psychic blindness" or "psychic deafness" occurred when the visual or the auditory area was partially damaged. The psychologists were the only people who freely discussed the activity of the hemispheres, although nobody understood the true nature of their functioning.

Another queer situation in the study of physiology at that period was that the chapters on the organs of sense had very little connection with the chapter on the central nervous system. Methods of investigation were different in these two fields, and the results obtained were often discussed from different points of view. What did Pavlov alter in this unfortunate blend of physiology and psychology, and what did he add to these sciences? The most important and difficult step which he took was to apply Descartes' conception of "reflex action" to the study of the functions of the hemispheres. This conception had been used by physiologists for generations to explain the processes taking place in practically 
all parts of the central nervous system except the hemispheres. Many times during the early stages of this work, and even years after its inception, Pavlov doubted whether he had taken the right course in applying physiological methods to the study of the highest part of the central nervous system; but innumerable facts discovered in his laboratories, and their successful interpretation from a purely physiological point of view, eventually persuaded him that the path which he had chosen was the right one.

In broad outline, Pavlov's conception of the function of the central nervous system was as follows. Its primary function is, in his own words, to "maintain a dynamic equilibrium between the functional units within the self-contained system of the organism as a whole and its environment" (Croonian Lecture, 1928). Two divisions of the central nervous system subserve the function of maintaining the fine relations of the body with the outer world in the higher vertebrates (except man, who possesses a third). The subcortical ganglia form one division; they are responsible for the most complex inborn reactions-usually called "instincts"-which are often concomitant with the emotional state of the animal. Pavlov regarded these reactions as very complicated unconditioned chain reflexes. A reaction of this type is evoked by one of a limited number of stimuli acting from without or within the body. The rôle of the subcortical ganglia in keeping the higher animal in equilibrium with its immediate environment is, however, subsidiary. An animal, deprived of the hemispheres, as for example a dog from which the cerebral cortex has been surgically removed, is very poorly equipped to adapt itself to its environment.

A much finer adjustment of the equilibrium is achieved through the activity of the hemispheres. The hemispheres (excluding the frontal lobes) represent the second functional division of the brain. A new principle concerning the activity of the central nervous system is here evolved, whereby any of the limited number of stimulants which provoke an unconditioned, inborn reflex may be combined temporarily with some of the innumerable phenomena occurring simultaneously in the surrounding medium. These phenomena become "signalling stimuli" - that is, signals for the occurrence of some bodily activity, such as muscular contraction, glandular secretion, and so on.

Pavlov thought that the hemispheres, at any rate in the dog, are occupied chiefly by the central ends of the "analysers," of which the peripheral ends are represented by the various "organs of sense." The hemispheres possess two fundamental properties, the properties of analysis and synthesis. Every phenomenon stimulating the organs of sense is 
analysed, partly at the periphery of the body, partly in the hemispheres. The synthetical activity of the hemispheres consists in combining with certain activities of the body the nervous process evoked in the hemispheres by a signalling stimulus. Thus is formed an excitatory complex, a conditioned reflex.

The hemispheres permit the animal to establish far finer and more accurate relations with its environment than do the subcortical ganglia. The animal's capacity of adaptation to its surroundings is thereby tremendously increased. This signalling system is possessed by all the higher vertebrates. But man has, in addition, another signalling system. We are justified in thinking that in man, with the development of the frontal lobes, another division has been added to the hemispheres. This takes care of the system of signalling known as speech, the basic components of which are the kinæsthetic impulses arising in the organs of speech. Thus, for example, a red light may be the signal of a flame, but the word "flame" is a signal of the red light, or the "signal of a signal." The ability to operate with the "signal of a signal" seems to be the exclusive property of the human brain. The analysis and synthesis and the generalization of these signals of signals greatly enlarges the scope of the brain's activity and the adaptability of the body to its environment. On these operations of the hemispheres the highest mental activities are based.

It has sometimes been said, unjustly, that Pavlov denied the claim of psychology to be called a science. What he actually did was to establish the right of physiology to investigate the activity of the hemispheres, using physiological methods and discussing the results obtained from a physiological point of view. His aim was to study by the method of conditioned reflexes the manifestations of the highest nervous activity in animals and man, both in normal and pathological conditions. Physiology and psychology represent two aspects of the same phenomena. The time will come when it will be possible to embroider on the plain canvas of physiological fact the complicated design of psychological phenomena, and thus accomplish a synthesis of these two departments of human biology.

While it is yet too early to estimate the full value of Pavlov's bold stroke of genius, it can be positively stated that his thirty years' study of the cerebral hemispheres in the dog by the method of conditioned reflexes gave science its first insight into the true physiology of the highest part of the central nervous system. Two books on conditioned reflexes were published by I. P. Pavlov: Conditioned Reflexes (translated by G. V. Anrep. Oxford University Press, 1927), and Lectures on Conditioned 
Reflexes (translated by W. Horsley Gantt. International Publishers, New York, 1928). The method is now firmly established in physiology and has opened up unlimited possibilities of further investigation. In the hands of many investigators it has already become one of the most useful tools for the study of phenomena occurring in the cerebral cortex. The influence of Pavlov's work in conditioned reflexes is already being noticeably felt in psychology, and there is little doubt that it will influence the psychologists more and more, as well as the psychiatrists, and eventually the pedagogues and sociologists.

These extraordinary achievements were the work of an extraordinary man. Pavlov was born on September 26, I849, in the provincial city of Riazan, in Central Russia. He graduated first from the science faculty of the University of St Petersburg, and afterwards (in 1879) from the Medico-Chirurgical Academy there. He studied physiology under Professor E. Cyon in Russia, and under Professors C. Ludwig and R. Heidenhain in Germany. In I 890 he became Professor of Pharmacology, and in 1895 Professor of Physiology, in the Military Medical (formerly Medico-Chirurgical) Academy of St Petersburg. In I 890 he had also been appointed head of the Department of Physiology at the Institute of Experimental Medicine in St Petersburg, a position which he held till the day of his death. Most of his work was done in this laboratory. Himself the son of a clergyman, he resigned his Chair of Physiology at the Military Medical Academy in 1924 as a protest against the persecution of the children of the clergy by the Soviet authorities, who denied them the right of entering the universities. He was a member of the Russian Academy of Science, the Royal Society of London, the Royal Society of Edinburgh, and many other learned societies and universities throughout the world. The life of Pavlov was not rich in adventure in the usual sense of the word, but it is a fascinating record of the adventures of a mind untiring in the search for truth.

All who met Pavlov, and especially those who had the honour of working under him, were impressed by his remarkable personality and the many capacities he possessed. He had an unusually retentive memory and a vivid imagination. His experimental ability and operative technique were quite exceptional. But the qualities that made him truly great were his power of concentration, with which was coupled an extraordinary analytical capacity, and his exclusive devotion to science. Pavlov himself often modestly remarked that he owed his scientific success to continuous and never-slackening meditation on his problems. The following incident shows how absorbed he usually was in his ideas. On one occasion I asked him how he had liked the opera, La Bohème, a 
performance of which he had attended the night before. "I think I liked it, but I cannot say definitely," he answered; "it was extremely difficult to listen to the music, because my thoughts were constantly turning to conditioned reflexes."

Facts, and facts only, governed all Pavlov's conceptions. He told us that he considered any theory good that could be kept alive for half a year. But he was not a slave to facts; they did not oppress him. $\mathrm{He}$ could marshall them, and by a process of unremitting and pitiless analysis draw from a chaotic mass of seemingly contradictory data a clear and definite conclusion.

Pavlov's devotion to science and his belief in it were extraordinary. He regarded the work of a scientist as a mission. This led him to require a very high standard of attainment both from himself and from those who worked under him. He was always ready to sacrifice his own interests in the cause of science, and many were the sacrifices he made. Let me quote his own words from the Preface to his Lectures on Conditioned Reflexes (p. 4I), where he refers to this new method of investigating the functions of the cerebral hemispheres.

"... I am deeply and irrevocably convinced that along this path will be found the final triumph of the human mind over its uttermost and supreme problem-the knowledge of the mechanism and laws of human nature. Only thus may come a full, true, and permanent happiness. Let the mind rise from victory to victory over surrounding nature, let it conquer for human life and activity not only the surface of the earth but all that lies between the depth of the seas and the outer limits of the atmosphere, let it command for its service prodigious energy to flow from one part of the universe to the other, let it annihilate space for the transference of its thoughts-yet the same human creature, led by dark powers to wars and revolutions and their horrors, produces for itself incalculable material losses and inexpressible pain and reverts to bestial conditions. Only science, exact science about human nature itself, and the most sincere approach to it by the aid of the omnipotent scientific method, will deliver man from his present gloom, and will purge him from his contemporary shame in the sphere of interhuman relations."

I realise that this brief notice is a far from adequate description of I. P. Pavlov and his work. I offer it merely as a humble tribute of respect and admiration to my great teacher and master.

Professor Pavlov was elected an Honorary Fellow of this Society in 1908.

See also Obituary Notices of Fellows of the Royal Society, vol. ii, No. $5,1936$.

B. P. B. I8 